\title{
Diffusion tensor imaging of normal-appearing cervical spinal cords in patients with multiple sclerosis: Correlations with clinical evaluation and cerebral diffusion tensor imaging changes. Preliminary experience
}

\author{
Michał Wolańczyk ${ }^{1, A-D, F}$, Joanna Bladowska, ${ }^{1, A, B}$, Anna Kołtowska, ${ }^{1, A-D}$, Anna Pokryszko-Dragan 2,E,F, \\ Przemysław Podgórski ${ }^{1, B, E}$, Sławomir Budrewicz ${ }^{2, E, F}$, Marek Sąsiadek ${ }^{1, A-F}$ \\ ${ }^{1}$ Department of General Radiology, Interventional Radiology and Neuroradiology, Wroclaw Medical University, Poland \\ 2 Department of Neurology, Wroclaw Medical University, Poland \\ A - research concept and design; $\mathrm{B}$ - collection and/or assembly of data; $\mathrm{C}$ - data analysis and interpretation; \\ $D$ - writing the article; $E$ - critical revision of the article; $F$ - final approval of the article
}

Address for correspondence Anna Kołtowska

E-mail:annakoltowska02@gmail.com

Funding sources

Supported by Wroclaw Medical University (grant No. ST.(270.17.041).

Conflict of interest

None declared

Received on May 26, 2019

Reviewed on June 4, 2019

Accepted on January 21, 2020

Published online on May 5, 2020

Cite as

Wolańczyk M, Bladowska J, Kołtowska A, et al. Diffusion tensor imaging of normal-appearing cervical spinal cords in patients with multiple sclerosis: Correlations with clinical evaluation and cerebral diffusion tensor imaging changes. Preliminary experience. Adv Clin Exp Med. 2020;29(4):441-448. doi:10.17219/acem/116754

DOI

10.17219/acem/116754

Copyright

Copyright by Author(s)

This is an article distributed under the terms of the

Creative Commons Attribution 3.0 Unported (CC BY 3.0)

(https://creativecommons.org/licenses/by/3.0/)

\begin{abstract}
Background. Several studies have identified changes in the spinal cord DTI measurements in patients with multiple sclerosis (MS). However, correlations between changes in DTI parameters in normal appearing cervical spine and neurological findings have not been clearly established.
\end{abstract}

Objectives. To determine whether diffusion tensor imaging (DTI) measurements such as fractional anisotropy (FA) and apparent diffusion coefficient $(A D C)$ are sufficiently sensitive in detecting microstructure alterations in normal-appearing spinal cords in patients with MS and whether they reflect these patients' clinical disability.

Material and methods. Fifteen patients diagnosed with relapsing-remitting MS (RRMS) with normalappearing cervical spinal cords on plain MRI and 11 asymptomatic volunteers were enrolled in the study. Overall, 75 cervical spinal segments were analyzed. The regions of interest were drawn from the entire spinal cord cross-section and in the normal-appearing white matter tracts: the superior and inferior cerebellar peduncles and the posterior limbs of the internal capsules. Neurological deficit and the level of disability were evaluated using the Expanded Disability Status Scale (EDSS), the timed 25-foot walk test (T25FW) and the 9-hole peg test (9HPT) for manual dexterity.

Results. A significant difference $(p<0.05)$ in FA values between patients with MS and the control group was found at levels C2 ( $p=0.047)$ and C3 ( $p=0.023)$. No significant changes in ADC values were found. There was correlation between FA and ADC values in selected white matter tracts and at particular spinal cord levels. We also observed significant correlations between diffusion tensor imaging parameters and manual dexterity.

Conclusions. Our preliminary results may suggest that the spinal cord's structural loss is the dominant factor in the inflammatory/demyelinating component in patients with MS. Diffusion tensor imaging changes in the spinal cord correlate with brain DTI changes. Manual functioning seems to be more affected than walking.

Key words: disability, walking, multiple sclerosis, spinal cord, diffusion tensor imaging 


\section{Introduction}

Multiple sclerosis (MS) is a chronic disease with a complex background, which is associated with the processes of immune-mediated inflammatory demyelination and axonal loss within the central nervous system (CNS). Multifocal damage to the brain and spinal cord, which develops over time in a relapsing-remitting or less frequently progressive manner, results in a diversity of symptoms and signs of neurological deficit, eventually leading to disability.

Magnetic resonance imaging (MRI) has become the modality of choice for detecting and assessing MS lesions within both the brain and the spinal cord, due to its sensitivity in detecting focal white matter lesions. However, changes observed in plain MRI often do not correlate with patients' clinical presentation, which is called the clinical-radiological paradox or mismatch. On the other hand, MS lesions might not be visible in the spinal cord due to its small volume, despite clinical signs of spinal cord impairment. ${ }^{1}$

Diffusion tensor imaging (DTI) is a method which is sensitive to microstructure alterations even within the normalappearing brain and spinal cord, which enables quantitative assessment of changes almost at the cellular level. The main DTI parameters are fractional anisotropy (FA) and apparent diffusion coefficient (ADC). Fractional anisotropy is a biomarker of white matter integrity, and lower FA values indicate impairment of the white matter fibers' integrity; ADC is a measure of diffusivity which therefore increases over the course of inflammatory/demyelinating processes. ${ }^{2}$

Several studies have identified changes in the spinal cord DTI measurements in patients with MS. ${ }^{3-10}$ However, correlations between changes in DTI parameters and neurological findings have not been clearly established. ${ }^{1,11-14}$ Some of these studies were not controlled trials. Moreover, relationships between quantitative clinical indices and DTI parameters within normal-appearing spinal cords have not been closely explored.

The aim of this preliminary study was to determine whether quantitative DTI measurements in normalappearing spinal cords of patients with MS are sensitive in detecting alterations to its microstructure and whether these values are related to the patients' disability indices. Another objective was to assess whether DTI values in normal-appearing spinal cords correlate with the corresponding cerebral ones (within the cortico-spinal and cerebello-spinal tracts).

\section{Material and methods}

The study was comprised of 15 patients diagnosed with relapsing-remitting MS (RRMS) according to the current McDonald criteria ${ }^{15}$ (14 women and 1 man; age range: 28-48 years, mean age: 35.45 years) and 11 asymptomatic volunteers as control subjects (CS) with no history of neurological disorder (10 women and 1 man; age range:
28-48 years, mean age: 34.2 years). In patients with MS, the duration of illness ranged from 3 to 15 years (mean: 7.06 years). The EDSS results were $1-4$ (mean: 2.26). All the patients and controls were right-handed.

The inclusion criterion for the study group was a lack of MS plaques or any other focal lesions in the spinal cord. The exclusion criteria were as follows: acute MS relapse and corticosteroid treatment within 3 months prior to inclusion in the study, the presence of marked cervical spine degenerative disease, previous spinal surgery or any incidental findings seen on plain MRI which would potentially suggest a neurological disorder.

The study was performed in accordance with the guidelines of the local University Ethics Committee for conducting research involving humans. All subjects provided their written informed consent to participate in this study according to the Helsinki Declaration, and the study was approved by the Local Commission of Bioethics.

\section{MRI and DTI protocol}

The MRI examinations were performed with a $1.5 \mathrm{~T}$ MRI (SignaHdx; GE Medical Systems, Chicago, USA) with a maximum gradient amplitude of $33 \mathrm{mT} / \mathrm{m}$, a $120 \mathrm{mT} / \mathrm{m} / \mathrm{s}$ slew rate and a 16-channel HNS coil. The MRI protocol for cervical spinal cord study consisted of sagittal T1-weighted images, sagittal and axial T2-weighted images and sagittal T2-weighted FAT SAT images, followed by axial DTI sequence. Acquisition of DTI was based on single-shot spinecho echo-planar imaging (SE/EPI) with the following settings: TR 10,000 ms; TE $100 \mathrm{~ms}, 160 \times 160 \mathrm{~mm}$ field of view (FOV), $96 \times 96 \mathrm{~mm}$ matrix, $1.6 \times 1.6 \mathrm{~mm}$ in-plane image resolution, $4 \mathrm{~mm}$ axial slices parallel to the intervertebral disk space, no gap and 2 acquisitions. The examination frame was adjusted to cover the length of the spinal cord from vertebrae C1 to C7. Diffusion was measured along 15 non-collinear directions using $b$ values of $0 \mathrm{~s} / \mathrm{mm}^{2}$ and $1,000 \mathrm{~s} / \mathrm{mm}^{2}$. The acquisition time of the sequence was about $7 \mathrm{~min}$.

In all patients, a conventional brain MRI was performed according to the standard protocol used in our department ${ }^{16}$ : sagittal and coronal T2 FRFSE sequences, axial T1 SE, T2 FSE and FLAIR sequences, axial DWI SE/EPI sequence and gadolinium-enhanced 3D-FSPGR sequence. The brain DTI acquisitions were performed using an axial single-shot spin-echo echo-planar imaging sequence (SE/EPI) along 25 different diffusion-encoding directions. For each direction, $2 b$ values were used: 0 and $1,000 \mathrm{~s} / \mathrm{mm}^{2}$ (4-mm slice thickness, no gap, TR 8,500 ms; TE 100,8 ms, $260 \times 208 \mathrm{~mm}$ field of view, $128 \times 128 \mathrm{~mm}$ matrix and 2 excitations). The acquisition time of DTI in each subject was 7.31 min. ${ }^{16}$

\section{Image analysis}

The image analysis was performed according to previously described methods. ${ }^{17}$ Plain MRIs of the cervical spine 


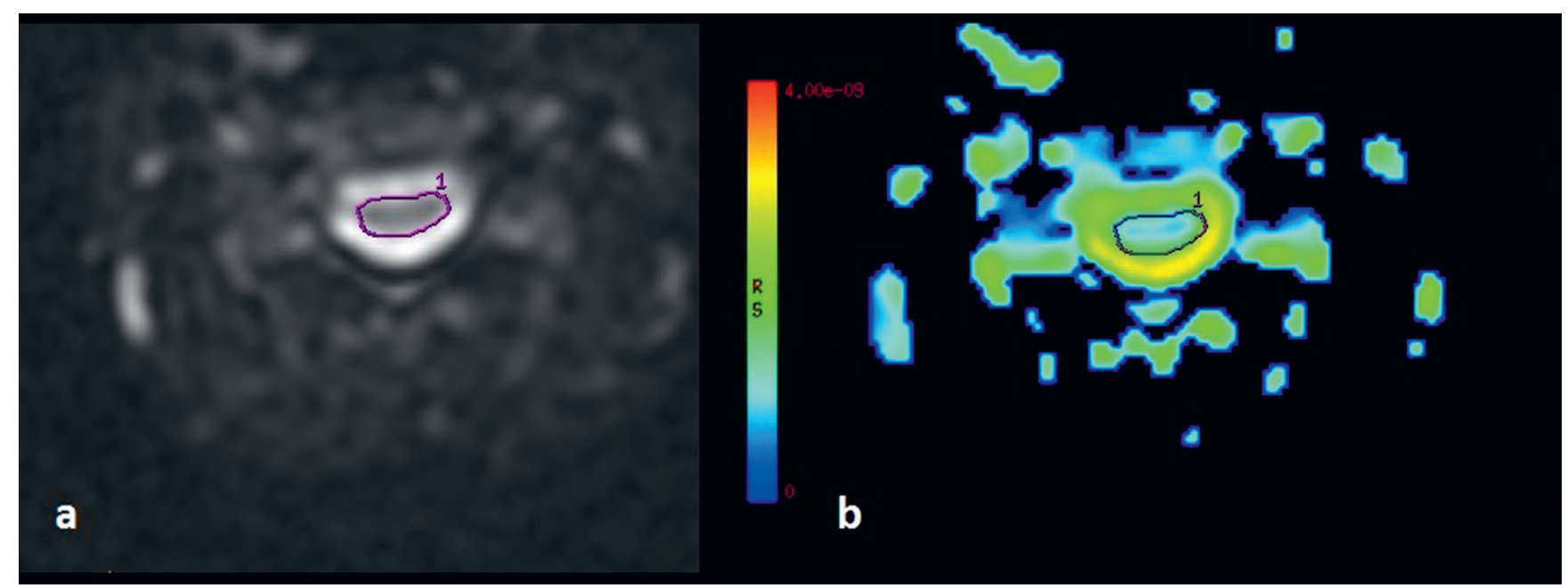

Fig. 1. Positioning of the regions of interest (ROI): a) b0 image and b) FA map. Each ROI was drawn manually over the entire axial cross-section of the cervical spinal cord, according to the most accurate axial bo image

and brains of the 15 patients and 11 age-matched control subjects were analyzed by 2 independent readers (M.W. and J.B.), who were blinded to the clinical results. Image post-processing was done using the Functool software (GE ADW 4.6 workstation; GE Healthcare). Apparent diffusion coefficient (ADC) and fractional anisotropy (FA) axial maps were generated; FA and ADC values at the selected spine segments and brain regions were calculated based on these axial maps.

The regions of interest (ROIs) were drawn over the entire axial spinal cord cross-section, according to the most accurate axial B0 image ${ }^{17}$ at about half of the height of each vertebral body, as shown in Fig. 1.

All levels with significant artifacts were excluded from further analysis. The vast majority of artifacts were found at level C7; therefore, we decided to exclude all C7 levels from further evaluation. In total, 75 spinal segments were analyzed.

Diffusion tensor imaging measurements in the brain were performed by placing ROIs of $10 \mathrm{~mm}^{2}$ in the following normal-appearing white matter regions: the right and left superior cerebellar peduncles (SCPR and SCPL), the right and left inferior cerebellar peduncles (ICPR and ICPL) and the right and left posterior limbs of the internal capsules (pyramidal cortico-spinal tracts (CSTs)) (PLICR and PLICL).

\section{Clinical data}

The type and duration of MS (duration of illness) were determined based on the patients' medical records. All patients underwent neurological examination, and their neurological deficit and level of disability were evaluated using the Expanded Disability Status Scale (EDSS). ${ }^{18}$ Functional tests ${ }^{19}$ were also performed to assess particular aspects of disability: the timed 25-foot walk (T25FW) for ambulation (the time needed to walk a distance of 25 feet, with an average of the results from 2 trials) and the 9-hole peg test (9HPT) for manual dexterity (the time needed to insert 9 pegs into holes and remove them using one hand, with an average of the results from 2 consecutive trials for the dominant and non-dominant hand).

\section{Statistical analysis}

Comparisons of the FA and ADC values of the same cervical spinal cord levels among all groups were performed using Student's t-test and the Mann-Whitney test. Correlations between spinal cord DTI parameters and clinical results, as well as DTI values in selected brain regions, were estimated using Pearson's correlation coefficient. STATISTICA v. 10 software (StatSoft, Inc., Tulsa, USA) was used for statistical calculations; a p-value $<0.05$ was considered statistically significant.

\section{Results}

There were no significant differences in age $(\mathrm{p}=0.66)$ or sex distribution between patients with MS and the control group.

\section{Comparison of FA and ADC values in the spinal cord between patients with MS and the control group}

The FA and ADC values at different levels (C1-C6) of the cervical spinal cord in patients with MS and controls, as well as statistical differences in these parameters between the 2 groups, are shown in Tables 1 and 2 .

In the MS group, the mean FA values ranged from 0.570 (C6 level) to 0.644 (C3 level) and the mean ADC values ranged from 0.947 (C1 level) to 1.078 (C6 level) $\left(\times 0.001 \mathrm{~mm}^{2} / \mathrm{s}\right)$. In the controls, the mean FA values ranged 
Table 1. Mean FA values within the spinal cords of patients with MS and the control group

\begin{tabular}{|l|c|c|c|}
\hline $\begin{array}{c}\text { Cervical } \\
\text { spine level }\end{array}$ & $\begin{array}{c}\text { Mean FA in MS } \\
\text { group }\end{array}$ & $\begin{array}{c}\text { Mean FA } \\
\text { in controls }\end{array}$ & p-value \\
\hline C1 & 0.635 & 0.641 & 0.884 \\
\hline C2 & 0.639 & 0.708 & $\mathbf{0 . 0 4 7}$ \\
\hline C3 & 0.644 & 0.694 & $\mathbf{0 . 0 2 3}$ \\
\hline C4 & 0.604 & 0.636 & 0.425 \\
\hline C5 & 0.599 & 0.650 & 0.062 \\
\hline C6 & 0.570 & 0.632 & 0.068 \\
\hline
\end{tabular}

Statistically significant differences are marked in bold; MS - multiple sclerosis; FA - fractional anisotropy.

from 0.632 (C6 level) to 0.708 (C2 level) and the mean ADC values ranged from 1.009 (C3 level) to 1.058 (C4 level) $\left(\times 0.001 \mathrm{~mm}^{2} / \mathrm{s}\right)$. Significantly lower FA values $(\mathrm{p}<0.05)$ were found at levels C2 and C3 in patients with MS than in the control subjects (Table 1). There were no significant changes in ADC values between the studied groups (Table 2).

\section{Correlations of DTI measurements in the spinal cord with outcomes of clinical evaluation in patients with MS}

The outcomes of clinical evaluation of each patient are shown in Table 3. Correlations between mean DTI values in the spinal cord and clinical outcomes in the MS group are presented in Table 4.
Table 2. Mean ADC values within the spinal cords of patients with MS and the control group

\begin{tabular}{|l|c|c|c|}
$\begin{array}{c}\text { Cervical } \\
\text { spine level }\end{array}$ & $\begin{array}{c}\text { Mean ADC } \\
\text { in MS group }\end{array}$ & $\begin{array}{c}\text { Mean ADC } \\
\text { in controls }\end{array}$ & p-value \\
\hline C1 & 0.947 & 1.030 & 0.417 \\
\hline C2 & 1.060 & 1.010 & 0.310 \\
\hline C3 & 1.045 & 1.009 & 0.399 \\
\hline C4 & 1.026 & 1.058 & 0.467 \\
\hline C5 & 1.048 & 1.029 & 0.632 \\
\hline C6 & 1.078 & 1.014 & 0.211 \\
\hline
\end{tabular}

FA - fractional anisotropy; ADC - apparent diffusion coefficient.

Significant negative correlations between the mean FA values in the spinal cord and the 9HPT test results were found at levels $\mathrm{C} 4$ and $\mathrm{C} 5$, for both the dominant and nondominant hands.

There was also a significant negative correlation between FA values at level C6 and the 9HPT test results for the dominant hand. No significant positive correlations between mean FA values in the spinal cord and clinical results were observed.

Significant positive correlations between the ADC values in the spinal cord and the 9HPT test results for the nondominant hand were found at levels C1, C2, C3, C4 and C6, and for the dominant hand at levels $\mathrm{C} 4$ and $\mathrm{C6}$. The ADC values at levels C4 and C5 also positively correlated with a longer duration of illness. There were no significant negative correlations between the mean ADC values in the spinal cord and the clinical outcomes.

Table 3. Clinical evaluation of patients with MS

\begin{tabular}{|c|c|c|c|c|c|}
\hline Patient & $\begin{array}{l}\text { T25FW } \\
{[s]}\end{array}$ & $\begin{array}{l}\text { 9HPT with dominant hand } \\
{[\mathrm{s}]}\end{array}$ & $\begin{array}{l}\text { 9HPT with non-dominant hand } \\
{[\mathrm{s}]}\end{array}$ & EDSS & $\begin{array}{l}\text { Duration of illness } \\
\text { [years] }\end{array}$ \\
\hline 1 & 5.6 & 19.6 & 21.3 & 1 & 3 \\
\hline 2 & 5.3 & 21.3 & 20.6 & 1.5 & 7 \\
\hline 3 & 4.9 & 20.5 & 22.4 & 3 & 11 \\
\hline 4 & 4.0 & 16.6 & 17.2 & 3 & 5 \\
\hline 5 & 4.2 & 23.6 & 28.9 & 1.5 & 8 \\
\hline 6 & 6.1 & 21.5 & 27.3 & 4 & 5 \\
\hline 7 & 7.1 & 31.7 & 32.5 & 1.5 & 14 \\
\hline 8 & 4.8 & 33.2 & 31.4 & 2 & 8 \\
\hline 9 & 5.2 & 29.1 & 29.3 & 3.5 & 15 \\
\hline 11 & 4.6 & 20.2 & 21.7 & 2.5 & 10 \\
\hline 12 & 5.4 & 21.5 & 19.2 & 2 & 3 \\
\hline 13 & 5.2 & 18.1 & 16.6 & 2 & 5 \\
\hline 14 & 4.0 & 19.2 & 19.1 & 1.5 & 6 \\
\hline 15 & 5.7 & 19.8 & 17.3 & 2.5 & 3 \\
\hline Median & 5.2 & 20.5 & 21.4 & 2.0 & 6.0 \\
\hline
\end{tabular}

T25FW - timed 25-foot walk test; 9HPT - 9-hole peg test; EDSS - Expanded Disability Status Scale. 
Table 4. Correlations between mean DTI values in the spinal cord and clinical outcomes in patients with MS

\begin{tabular}{|c|c|c|c|c|c|c|c|c|c|c|c|}
\hline \multirow{2}{*}{\multicolumn{2}{|c|}{$\begin{array}{l}\text { Cervical spine } \\
\text { level }\end{array}$}} & \multicolumn{2}{|c|}{ T25FW } & \multicolumn{2}{|c|}{$\begin{array}{l}\text { 9HPT, dominant } \\
\text { hand }\end{array}$} & \multicolumn{2}{|c|}{$\begin{array}{l}\text { 9HPT, non-dominant } \\
\text { hand }\end{array}$} & \multicolumn{2}{|c|}{ EDSS } & \multicolumn{2}{|c|}{ Duration of illness } \\
\hline & & PCC & $\mathrm{p}$-value & PCC & $\mathrm{p}$-value & PCC & $p$-value & PCC & $\mathrm{p}$-value & PCC & $\mathrm{p}$-value \\
\hline \multirow{2}{*}{$\mathrm{C} 1$} & FA & -0.5412 & 0.086 & -0.2914 & 0.385 & -0.4049 & 0.217 & -0.4199 & 0.198 & -0.0756 & 0.825 \\
\hline & ADC & 0.4674 & 0.147 & 0.4371 & 0.179 & 0.6382 & 0.035 & 0.3044 & 0.363 & 0.1898 & 0.576 \\
\hline \multirow{2}{*}{ C2 } & FA & 0.1809 & 0.595 & -0.2524 & 0.454 & -0.5221 & 0.099 & -0.0977 & 0.775 & -0.256 & 0.447 \\
\hline & ADC & 0.3854 & 0.242 & 0.47 & 0.145 & 0.6613 & 0.027 & 0.2189 & 0.518 & 0.1284 & 0.707 \\
\hline \multirow{2}{*}{ C3 } & FA & -0.2639 & 0.433 & -0.483 & 0.132 & -0.555 & 0.076 & -0.3941 & 0.230 & -0.2735 & 0.416 \\
\hline & ADC & -0.009 & 0.979 & 0.5829 & 0.060 & 0.6373 & 0.035 & 0.3232 & 0.332 & 0.4583 & 0.156 \\
\hline \multirow{2}{*}{ C4 } & FA & -0.1142 & 0.738 & -0.8626 & 0.001 & -0.7529 & 0.007 & -0.0811 & 0.813 & -0.5435 & 0.084 \\
\hline & ADC & 0.1294 & 0.705 & 0.8897 & 0.001 & 0.8287 & 0.002 & 0.041 & 0.905 & 0.6583 & 0.028 \\
\hline \multirow{2}{*}{ C5 } & FA & -0.0863 & 0.801 & -0.8467 & 0.001 & -0.7209 & 0.012 & -0.0654 & 0.848 & -0.4814 & 0.134 \\
\hline & ADC & -0.0573 & 0.867 & 0.0534 & 0.876 & 0.3643 & 0.271 & 0.5587 & 0.074 & 0.1901 & 0.576 \\
\hline \multirow{2}{*}{ C6 } & FA & -0.2115 & 0.533 & -0.6287 & 0.038 & -0.4551 & 0.160 & 0.2392 & 0.479 & -0.212 & 0.531 \\
\hline & ADC & -0.1285 & 0.707 & 0.7331 & 0.010 & 0.6859 & 0.020 & -0.1958 & 0.564 & 0.7921 & 0.004 \\
\hline
\end{tabular}

Statistically significant differences are marked in bold; C1-C6 - levels of the cervical spinal cord; FA - fractional anisotropy values; ADC - apparent diffusion coefficient values; EDSS - expanded disability status scale score; T25FW - timed 25-foot walk test; 9HPT - 9-hole peg test; PCC - Pearson correlation coefficient.

\section{Correlations between mean DTI parameters in the spinal cord and selected white matter tracts}

Within the white matter tracts, the mean FA values ranged from 0.570 to 0.658 , and for selected white matter locations the values were as follows: ICPR -0.57 ; ICPL - 0.64; SCPR - 0.59; SCPL - 0.60; PLICR - 0.65; and PLICL -0.66 (Table 5).

Significant positive correlations were found between the mean FA values in SCPR and the FA values in the spinal cord at level $\mathrm{C} 2$, between FA values in ICPL and FA values in the spinal cord at levels $\mathrm{C} 4$ and $\mathrm{C} 5$, and between FA values in PLICL and FA values in the spinal cord at level C6, which means that spinal FA values were lower in patients with lower FA values in the cerebral white matter tracts.
Within the brain regions which were analyzed, the mean $\mathrm{ADC}$ values ranged from 0.71 to 1.26 , and for the selected locations the values were as follows: ICPR -0.87 ; ICPL -0.77 ; SCPR - 1.26; SCPL - 1.11; PLICR - 0.71; and PLICL - 0.72 .

Significant positive correlations were found between the mean ADC values in PLICR and the ADC values in the spinal cord at levels $\mathrm{C} 1, \mathrm{C} 3$ and $\mathrm{C} 4$, between the ADC values in PLICL and the ADC values in the spinal cord at levels $\mathrm{C} 2$ and $\mathrm{C} 3$, and between the ADC values in ICPL and the ADC values in the spinal cord at level $\mathrm{C} 4$, which means that $\mathrm{ADC}$ values in the spinal cord were higher in patients with higher ADC values in the cerebral white matter tracts.

There were no significant negative correlations found between ADC values in the spinal cord and ADC values in the examined brain regions.

Table 5. Correlations between mean FA values in the spinal cord (levels C1 to C6) and brain white matter tracts

\begin{tabular}{|c|c|c|c|c|c|c|c|c|c|c|c|c|}
\hline \multirow{2}{*}{$\begin{array}{l}\text { Cervical } \\
\text { spina level } \\
\text { FA value }\end{array}$} & \multicolumn{2}{|c|}{$\begin{array}{c}\text { ICPR } \\
\text { FA }\end{array}$} & \multicolumn{2}{|c|}{$\begin{array}{c}\mathrm{ICPL} \\
\mathrm{FA} \\
\end{array}$} & \multicolumn{2}{|c|}{$\begin{array}{c}\text { SCPR } \\
\text { FA }\end{array}$} & \multicolumn{2}{|c|}{$\begin{array}{c}\text { SCPL } \\
\text { FA } \\
\end{array}$} & \multicolumn{2}{|c|}{$\begin{array}{c}\text { PLICR } \\
\text { FA } \\
\end{array}$} & \multicolumn{2}{|c|}{$\begin{array}{c}\text { PLICL } \\
\text { FA } \\
\end{array}$} \\
\hline & PCC & $\mathrm{p}$-value & PCC & $\mathrm{p}$-value & PCC & $p$-value & PCC & $p$-value & PCC & $\mathrm{p}$-value & PCC & $\mathrm{p}$-value \\
\hline C1 FA & 0.128 & 0.708 & 0.1733 & 0.610 & 0.3392 & 0.307 & 0.135 & 0.692 & 0.0724 & 0.833 & 0.4236 & 0.194 \\
\hline $\mathrm{C} 2 \mathrm{FA}$ & -0.0937 & 0.784 & 0.4463 & 0.169 & 0.6157 & 0.044 & 0.4477 & 0.167 & 0.3157 & 0.344 & 0.1656 & 0.627 \\
\hline C3 FA & 0.1592 & 0.640 & 0.295 & 0.378 & 0.0674 & 0.844 & -0.1179 & 0.730 & -0.012 & 0.972 & 0.2659 & 0.429 \\
\hline C4 FA & 0.1959 & 0.564 & 0.6405 & 0.034 & 0.2448 & 0.468 & -0.209 & 0.537 & 0.1347 & 0.693 & 0.193 & 0.570 \\
\hline C5 FA & 0.215 & 0.526 & 0.6381 & 0.035 & 0.2697 & 0.423 & -0.1817 & 0.593 & 0.284 & 0.397 & 0.3444 & 0.300 \\
\hline C6 FA & 0.2397 & 0.478 & 0.2797 & 0.405 & -0.1359 & 0.690 & -0.4744 & 0.140 & 0.4093 & 0.211 & 0.6947 & 0.018 \\
\hline
\end{tabular}

Statistically significant differences are marked in bold; C1-C6 - levels of the cervical spinal cord; FA - fractional anisotropy values; SCPR/SCPL - right/left superior cerebellar peduncles; ICPR/ICPL - right/left inferior cerebellar peduncles; PLICR/PLICL - right/left posterior limbs of internal capsules;

PCC - Pearson correlation coefficient. 
Table 6. Correlations between mean ADC values in the spinal cord (levels C1 to C6) and the brain

\begin{tabular}{|c|c|c|c|c|c|c|c|c|c|c|c|c|}
\hline \multirow{2}{*}{$\begin{array}{l}\text { Cervical } \\
\text { spinal level } \\
\text { ADC value }\end{array}$} & \multicolumn{2}{|c|}{$\begin{array}{l}\text { ICPR } \\
\text { ADC }\end{array}$} & \multicolumn{2}{|c|}{$\begin{array}{l}\mathrm{ICPL} \\
\mathrm{ADC}\end{array}$} & \multicolumn{2}{|c|}{$\begin{array}{l}\text { SCPR } \\
\text { ADC }\end{array}$} & \multicolumn{2}{|c|}{$\begin{array}{l}\text { SCPL } \\
\text { ADC }\end{array}$} & \multicolumn{2}{|c|}{$\begin{array}{c}\text { PLICR } \\
\text { ADC }\end{array}$} & \multicolumn{2}{|c|}{$\begin{array}{c}\text { PLICL } \\
\text { ADC }\end{array}$} \\
\hline & PCC & $p$-value & PCC & p-value & PCC & p-value & PCC & p-value & PCC & p-value & PCC & $p$-value \\
\hline C1 ADC & 0.2717 & 0.419 & 0.1413 & 0.679 & 0.0607 & 0.859 & -0.3826 & 0.246 & 0.652 & 0.030 & 0.489 & 0.127 \\
\hline$C 2 \mathrm{ADC}$ & 0.3103 & 0.353 & 0.2404 & 0.476 & 0.1777 & 0.601 & -0.2385 & 0.480 & 0.5552 & 0.076 & 0.6661 & 0.025 \\
\hline C3 ADC & -0.0518 & 0.880 & 0.5132 & 0.106 & 0.0808 & 0.813 & -0.5963 & 0.053 & 0.8303 & 0.002 & 0.7517 & 0.008 \\
\hline C5 ADC & -0.3967 & 0.227 & -0.02 & 0.953 & -0.2161 & 0.523 & -0.3959 & 0.228 & 0.579 & 0.062 & 0.4795 & 0.136 \\
\hline C6 ADC & -0.087 & 0.799 & 0.4599 & 0.155 & -0.4038 & 0.218 & -0.5568 & 0.075 & 0.5435 & 0.084 & 0.1459 & 0.669 \\
\hline
\end{tabular}

Statistically significant differences are marked in bold; C1-C6 - levels of the cervical spinal cord; ADC - apparent diffusion coefficient values; SCPR/SCPL - right/left superior cerebellar peduncles; ICPR/ICPL - right/left inferior cerebellar peduncles; PLICR/PLICL - right/left posterior limbs of internal capsules; PCC - Pearson correlation coefficient.

\section{Discussion}

Because MS onset mainly occurs in young adults, and due to the long-term and highly variable course of the disease, there is a need to diagnose and possibly predict at an early stage the extent of damage to the CNS and its clinical consequences. ${ }^{20}$ Early DTI changes reflect microstructural changes found at almost the cellular level, and FA value could potentially be a noninvasive biomarker for detecting subtle axonal lesions which may precede focal demyelination likely appearing later on as MS plaques on T2 sequences.

In this study, we investigated quantitative DTI indices such as FA and ADC values, measured at different levels of normal-appearing cervical spinal cords and in selected normal-appearing cerebral white matter tracts. This data correlated with functional measures of the degree of overall disability (EDSS), ambulation (T25FW) and manual dexterity (9HPT). Spinal cord atrophy is a well-known contributor to disability ${ }^{3,21}$; however, the conventional indices of spinal cord atrophy reflect tissue loss that is more likely to be irreversible. Measuring DTI parameters within a normal-appearing spinal cord may have the advantage of detecting potentially reversible changes which are not visible on conventional MRI scans.

Significant differences in FA values between patients with MS with normal-appearing spinal cords and controls were found at spinal levels C2 and C3. These results are in agreement with previous DTI studies showing decreased FA values in both normal-appearing spinal cords and in T2-visible lesions in the spinal cords of subjects with MS. ${ }^{6-10}$ On the other hand, we found no significant differences between the ADC values of the studied groups. Lower FA values in MS reflect axonal impairment, which corresponds to functional discontinuity of the axons and, by definition, is a more specific measurement than ADC, which increases due to the inflammatory/demyelinating processes. Therefore, our results may suggest that the axonal loss within the spinal cords of patients with MS is more pronounced than the inflammatory-demyelinating component. The other mechanism which could contribute to the lower FA values is Wallerian degeneration. However, the patients have no visible demyelinating lesions in the spinal cord - only the brain lesions; therefore, it seems rather unlikely.

Our results suggest a correlation between ADC values at levels $\mathrm{C} 4$ and $\mathrm{C} 6$ and the duration of illness, since the spinal ADC values appear to be higher in patients with a longer duration of illness. This may reflect increasing neuronal damage with a longer duration of disease.

In the next part of our study, we analyzed FA and ADC values of the spinal cord as related to various measurements of disability in the course of MS. Our data showed significant FA and ADC correlations with manual dexterity, as measured with the 9HPT. Particularly pronounced correlations were found between the higher ADC values in the spinal cord and manual dexterity at the levels of $\mathrm{C} 1$, C2, C3 and C6. Correlations between FA values and manual dexterity parameters were found only at levels C4 and C5.

Walking dysfunction is a relatively common problem in patients with MS, yet there is still a poor understanding of the possible neuronal substrate of walking., ${ }^{4,5,14}$ In this study, we did not find any significant correlations of DTI parameters in the spinal cord with the timed 25-foot walk test (T25FW) or the Expanded Disability Status Scale (EDSS). The EDSS score is strongly affected by ambulation ability, so the lack of correlations for both the EDSS and the T25FW is consistent. Our results seem to suggest that a loss of neuronal integrity within the cervical spinal cord is associated with greater impairment in manual dexterity than in walking ability.

The vast majority of available studies investigating the relationships between clinical parameters and DTI changes in patients with MS are primarily focused on the brain and not on the spinal cord. Hubbard et al. ${ }^{14}$ evaluated different DTI values of the corticospinal tract, including mean diffusivity (MD), radial diffusivity (RD), axial diffusivity (AD) and FA and their relationships with ambulation test scores (the T25FW and the 6-minute walk test). ${ }^{14}$ Although they found some significant correlations 
between the walking test results and RD and AD values, none were observed for FA values in the corticospinal tract, which seems to be consistent with our results.

Additionally, we investigated the relationships between DTI values in the spinal cord and corresponding pathways in the brain. A significant correlation was observed between lower FA values in the inferior cerebellar peduncle (ICP) and at levels C4 and C5 of the spinal cord. Such an association may suggest neuronal disintegration along the posterior spinocerebellar tract, running predominantly through the ICP. A significant correlation was also noted between the lower FA values in the superior cerebellar peduncle (SCP) and level C2 of the spinal cord, which in turn may be related to changes in the integrity of the anterior spinocerebellar tract. ${ }^{22,23}$ A considerable positive correlation was found between ADC values within the ICP and level $\mathrm{C} 4$ of the spinal cord, with corresponding higher ADC values in both regions. Although this correlation was found only at 1 level, it might suggest the involvement of the spinocerebellar tracts by disease, which could contribute to MS-related disability.

Our study also revealed correlations between ADC values within the spinal cord (levels C1, C2, C3 and C4) and in both posterior limbs of the internal capsules (PLICs). This association may depend on the anatomical structure of the pyramidal tracts, as more than half of their fibers terminate in the cervical spinal cord to supply the upper extremities. ${ }^{23}$ In comparison to other studies which evaluated cervical spinal cord changes at 1 or 2 levels of the cervical spinal cord, ${ }^{9,34-36}$ our study provides an assessment of pathological changes within a wider range of the cervical spinal cord (levels C1 to C6), which renders a more comprehensive look into changes that may contribute to clinical dysfunction.

As a preliminary report, our study features a number of limitations. The small sample size is likely to limit the statistical significance of the findings. Additionally, the use of ROIs encircling the cross-sectional area of the spinal cord- instead of particular columns - might have possibly created a bias in the observed structure-function relationships, although we believe this approach provides us with a more comprehensive view of spinal cord changes, assessing both white matter and grey matter. This approach has been already discussed in the literature, including our previous experience. ${ }^{17}$ Besides, it has been shown that MS affects both white matter and grey matter; therefore, the impairment of all spinal cord structures is calculated with our method. The involvement of the spinal cord grey matter (GM) in MS had already been recognized by the turn of the $20^{\text {th }}$ century, which is discussed in a study by Schlaeger et al. ${ }^{24}$ Other authors have reported a similar reduction of both grey matter and white matter cross-sectional cervical cord areas in advanced, progressive MS, with a predominance of GM loss. ${ }^{26-33}$

Nevertheless, the results seem to be interesting and to encourage further investigation. They suggest the need to explore spinal cord-specific pathological processes, mainly with regard to clinical disability in patients with a normalappearing spinal cord on plain MRI. Studies on a larger base of material, using an improved DTI evaluation protocol, may improve our understanding of the inflammatory and neurodegenerative processes underlying disability in MS.

\section{Conclusions}

Our preliminary findings show significant differences in FA values between the normal-appearing spinal cords of patients with MS and healthy controls. These may suggest that the structural loss within the spinal cords of patients with MS is of greater importance than the inflammatory-demyelinating component. The initial loss of neuronal integrity within the cervical spinal cord seems to influence manual dexterity more than walking function. Further studies are necessary to establish the role of DTI measures as biomarkers of the subtle alterations in the spinal cord integrity of patients with MS and their clinical and prognostic relevance.

\section{ORCID iDs}

Michał Wolańczyk (D) https://orcid.org/0000-0002-4296-3353 Joanna Bladowska (D) https://orcid.org/0000-0003-0597-8457 Anna Kołtowska (D) https://orcid.org/0000-0003-2508-9817 Anna Pokryszko-Dragan (D) https://orcid.org/0000-0002-5203-112X Przemysław Podgórski (D) https://orcid.org/0000-0002-9303-8432 Sławomir Budrewicz (D) https://orcid.org/0000-0002-2044-6347 Marek Sąsiadek (D) https://orcid.org/0000-0003-3627-118X

\section{References}

1. Oh J, Saidha S, Chen M, et al. Spinal cord quantitative MRI discriminates between disability levels in multiple sclerosis. Neurology. 2013;80(6):540-547. doi:10.1212/WNL.0b013e31828154c5

2. Banaszek A, Bladowska J, Podgórski P, Sąsiadek MJ. Role of diffusion tensor MR imaging in degenerative cervical spine disease: A review of the literature. Clin Neuroradiol. 2016;26(3):265-276. doi:10.1007/ s00062-015-0467-y

3. Filippi M, Bozzali M, Horsfield MA, et al. A conventional and magnetization transfer MRI study of the cervical cord in patients with MS. Neurol. 2000;54(1):207-213.

4. Hobart JC, Riazi DL, Lamping R, Fitzpatrick R, Thompson AJ. Measuring the impact of MS on walking ability: The 12-Item MS Walking Scale (MSWS-12). Neurology. 2003;60(1):31-36.

5. Motl RW. Ambulation and multiple sclerosis. Phys Med Rehabil Clin N Am. 2013;24(2):325-336.

6. Agosta F, Benedetti B, Rocca MA, et al. Quantification of cervical cord pathology in primary progressive MS using diffusion tensor MRI. Neurology. 2005;64(4):631-635.

7. Benedetti $B$, Valsasina $P$, Judica $E$, et al. Grading cervical cord damage in neuromyelitis optica and MS by diffusion tensor MRI. Neurology. 2006;67(1):161-163.

8. Ciccarelli O, Wheeler-Kingshott CA, McLean MA, et al. Spinal cord spectroscopy and diffusion-based tractography to assess acute disability in multiple sclerosis. Brain. 2007;130(Pt 8):2220-2231.

9. Hesseltine SM, Law M, Babb J, et al. Diffusion tensor imaging in multiple sclerosis: Assessment of regional differences in the axial plane within normal-appearing cervical spinal cord. AJNR Am J Neuroradiol. 2006;27(6):1189-1193.

10. Raz E, Bester M, Sigmund EE, et al. A better characterization of spinal cord damage in multiple sclerosis: A diffusional kurtosis imaging study. AJNR Am J Neuroradiol. 2013;34(9):1846-1852. doi:10.3174/ ajnr.A3512 
11. von Meyenburg J, Wilm BJ, Weck A, et al. Spinal cord diffusiontensor imaging and motor-evoked potentials in multiple sclerosis patients: Microstructural and functional asymmetry. Radiology. 2013;267(3):869-879. doi:10.1148/radiol.13112776

12. Oh J, Zackowski K, Chen M, et al. Multi-parametric MRI correlates of sensor motor function in the spinal cord in multiple sclerosis. Mult Scler. 2013;19(4):427-435. doi:10.1177/1352458512456614

13. Pardini M, Yaldizli Ö, Sethi V. Motor network efficiency and disability in multiplesclerosis. Neurology. 2015;85(13):1115-1122. doi:10.1212/WNL

14. Hubbard EA, Wetter NC, Sutton BP. Diffusion tensor imaging of the corticospinal tract and walking performance in multiple sclerosis. J Neurol Sci. 2016;15:225-231. doi:10.1016/j.jns.2016.02.044

15. Thompson AJ, Banwell BL, Barkhof F, et al. Diagnosis of multiple sclerosis: 2017 revisions of the McDonald criteria. Lancet Neurol. 2018;17(2):162-173. doi:10.1016/S1474-4422(17)30470-2

16. BanaszekA, BladowskaJ,Pokryszko-Dragan A,PodemskiR, SąsiadekMJ. Evaluation of the degradation of the selected projectile, commissural and association white matter tracts within normal appearing white matter in patients with multiple sclerosis using diffusion tensor MR imaging: A preliminary study. Pol J Radiol. 2015;80:457-463. doi:10.12659/PJR.894661

17. Banaszek A, Bladowska J, Szewczyk P, Podgorski P, Sasiadek M. Usefulness of diffusion tensor MR imaging in the assessment of intramedullary changes of the cervical spinal cord in different stages of degenerative spine disease. Eur Spine J. 2014;23(7):1523-1530. doi: 10.1007/s00586-014-3323-x

18. Kurtzke JF. Rating neurologic impairment in multiple sclerosis: An expanded disability status scale (EDSS). Neurology. 1983;33(11):1444-1452.

19. Fischer JS, Rudick RA, Cutter GR, Reingold SC. The Multiple Sclerosis Functional Composite Measure (MSFC): An integrated approach to MS clinical outcome assessment. National MS Society Clinical Outcomes Assessment Task Force. Mult Scler. 1999;5(4):244-250.

20. Johns P. Clinical Neuroscience. New York, NY: Elsevier; 2014.

21. Nijeholt GJ, Bergers E, Kamphorst W, et al. Post-mortem high-resolution MRI of the spinal cord in multiple sclerosis: A correlative study with conventional MRI, histopathology and clinical phenotype. Brain. 2001;124(Pt 1):154-166.

22. Tovar-Moll F, Evangelou IE, Chiu AW, et al. Diffuse and focal corticospinal tract disease and its impact on patient disability in multiple sclerosis. J Neuroimaging. 2015;25(2):200-206.
23. Kahle W, Frotscher M. Color Atlas of Human Anatomy. Vol. 3. Nervous System and Sensory Organs. 7th ed. New York, NY: Thieme; 2015.

24. Schlaeger R, Papinutto N, Panara V, et al. Spinal cord gray matter atrophy correlates with multiple sclerosis disability. Ann Neurol. 2014;76(4):568-580. doi:10.1002/ana.24241

25. Dejerine J. Etude sur la scléroseen plaques cérébrospinale à forme de sclérose latérale amyotrophique. Rev de Méd. 4:193;1884.

26. Brauer L. Muskelatrophie bei multipler Sklerose. Neuro Centralbl. 17:635;1898.

27. Bouchaud S. Scléroseen plaques avec amyotrophique. J de Neurol. 5:348; 1900 .

28. Lejonne MP. Contribution à l'étude des atrophies musculairesdans la scléroseen plaques. Thèse de Paris: G. Steinheil; 1903.

29. Davison C, Goodhart SP, Lander J. Multiple sclerosis and amyotrophies. Arch NeurPsych. 1934;31(2):270-289. doi:10.1001/archneurpsyc. 1934.02250020058003

30. Gilmore CP, Donaldson I, Bö L, Owens T, Lowe J, Evangelou N. Regional variations in the extent and pattern of grey matter demyelination in multiple sclerosis: A comparison between the cerebral cortex, cerebellar cortex, deep grey matter nuclei and the spinal cord. J Neurol Neurosurg Psychiatry. 2009;80(2):182-187.

31. Gilmore CP, DeLuca GC, Bö L, et al. Spinal cord neuronal pathology in multiple sclerosis. Brain Pathol. 2009;19(4):642-649.

32. Gilmore CP, DeLuca GC, Bö L, et al. Spinal cord atrophy in multiple sclerosis caused by white matter volume loss. Arch Neurol. 2005;62(12):1859-1862.

33. Bjartmar C, Kidd G, Mörk S, Rudick R, Trapp BD. Neurological disability correlates with spinal cord axonal loss and reduced $\mathrm{N}$-acetyl aspartate in chronic multiple sclerosis patients. Ann Neurol. 2000;48(6): 893-901.

34. Oh J, Sotirchos ES, Saidha S. Relationships between quantitative spinal cord MRI and retinal layers in multiple sclerosis. Neurology. 2015;84(7):720-728. doi: 10.1212/WNL

35. Klineova S, Farber R, Saiote C, et al. 2016. Relationship between timed 25 -foot walk and diffusion tensor imaging in MS. Mult Scler J Exp Trans/Clin. 2016;2:2055217316655365. doi:10.1177/2055217316655365

36. Fritz NE, Kellera J, Calabresid PA, Zackowskia KM. Quantitative measures of walking and strength provide insight into brain cortico-spinal tract pathology in multiple sclerosis. Neuroimage Clin. 2017;14:490-498. doi:10.1016/j.nicl.2017.02.006 